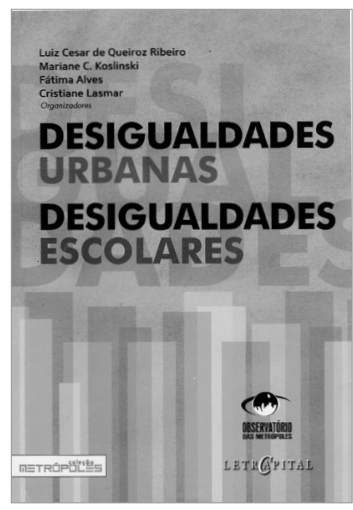

Os efeitos dos processos de segmentação territorial e segregação residencial sobre as oportunidades de escolarização de crianças e jovens do sistema público de ensino é o tema do livro Desigualdades Urbanas, Desigualdades Escolares, organizado por pesquisadores da rede do Observatório das Metrópoles.

Conjugando as vertentes da sociologia e antropologia urbana e da sociologia da educação, o livro se insere em uma nova geração de estudos que partem com o argumento de que a distribuição desigual da população no espaço urbano gera efeitos sobre as condições objetivas e subjetivas dos indivíduos, influenciando os resultados escolares.

Esses estudos procuram demonstrar que além da escola e da família, o espaço social conformado pela divisão socioterritorial das cidades é importante para as reflexões acerca das chances de escolarização, especialmente de crianças e adolescentes de segmentos sociais vulneráveis, residentes das regiões segregadas das cidades.

Tendo a metrópole do Rio de Janeiro como cenário, os artigos que compõem a coletâ-

\section{Desigualdades urbanas, Desigualdades ESCOLARES}

\section{Luiz Cesar de Queiroz Ribeiro, Mariane C. Koslinski, Fatima Alves, Cristiane Lasmar (Organizadores)}

Letra Capital: Observatório das Metrópoles | Rio de JANEIRo (2010).

nea apresentam resultados de quatro anos de pesquisas no tema. Pode-se definir como proposta principal dos artigos a investigação empírica da hipótese de que os resultados escolares são afetados não só pelos capitais culturais e sociais baseados na família, mas também baseados na escola e na comunidade mais ampla (vizinhança).

O livro está disposto em duas partes: a primeira denominada Da cidade à escola, composta por seis artigos que utilizam metodologia quantitativa, mapeando o território e tomando-o como expressão de uma distribuição desigual de recursos sociais e de equipamentos urbanos, especialmente os escolares. A segunda parte, denominada Da escola à cidade está composta por três artigos que trazem resultados de estudos de casos de viés etnográfico, em bairros de classe popular da metrópole do Rio de Janeiro, com o propósito de iluminar mecanismos que geram padrões locais de relacionamento com a instituição escolar.

Em A Metropolização da questão social e as desigualdades de oportunidades educacionais no Brasil, Luiz Cesar Ribeiro e Mariane Koslinski abordam os efeitos e ten- 
dências à metropolização da questão social no Brasil, sobre as desigualdades de acesso às oportunidades educacionais. As análises dos dados oficiais de avaliações das escolas no Brasil permitiram observar as diferenças de resultados escolares entre municípios metropolitanos e não metropolitanos. Os autores sugerem uma tendência de desempenho escolar mais baixo nos municípios integrados à dinâmica metropolitana, sobretudo nas regiões Sudeste, Sul e Centro-oeste. As possíveis causas do que denominam efeito metrópole está na relação entre o processo de desorganização e desestabilização da vida social nesses locais, especialmente em territórios que concentram as camadas populares.

Nesta mesma direção, Ribeiro \& Koslinski buscam compreender em seu segundo artigo na coletânea, as oportunidades educacionais frente à geografia da cidade do Rio de Janeiro, cuja organização social é muito particular. Esta particularidade se dá pelo modelo centro-periferia e pelo modelo de aparente heterogeneidade vivido em certos espaços em que há presença de favelas em regiōes abastadas da cidade. As análises dos dados na macro-escala apontam que escolas situadas em entornos menos privilegiados e que concentram domicílio de clima educativo baixo, apresentam, em média, menor proficiência. Os resultados na micro-escala revelam que a localização de escola até 100 metros de favelas também apresentam menor proficiência. Com isto, os autores observam que as desigualdades escolares estão em maior medida nos bairros mais afastados do centro, porém esta tendência não é acompanhada por uma equidade entre as escolas. Isto porque escolas em regiões centrais, porém próximas ou dentro de favelas, também apresentam baixo desempenho. Neste sentido, o artigo mostra que a organização do território, além de promover maior desigualdade das chances de escolarização, promove a segmentação entre as escolas.

Ainda no tema da geografia da cidade do Rio de Janeiro, os autores Fátima Alves,
Wolfran Lange e Alicia Bonamino fornecem a compreensão da dinâmica entre oferta e demanda escolar no território carioca. Utilizando como metodologia as ferramentas de geoprocessamento - SIG, os autores buscaram operacionalizar o conceito de geografia objetiva de oportunidades educacionais, desenvolvido por FLORES (2008). Ao construirem um índice de oportunidade educacional, combinando demanda de crianças de 6 a 14 anos e ofertas de escolas, Alves, Lange $\&$ Bonamino apontam no artigo Geografia objetiva de oportunidades educacionais na cidade do Rio de Janeiro que existe baixa oferta de escolas públicas em comparação às privadas. Os dados mostram a tendência das áreas localizadas em favelas com o perfil de alta demanda e baixa oferta, ao passo que a relação estável entre demanda e oferta está em áreas mais consolidadas da cidade.

A distribuição das oportunidades escolares, assim como de oportunidades de emprego aos jovens de classes populares, é a base da investigação de Andre Salata e Maria Josefina Sant'Anna no artigo Entre o mercado de trabalho e a escola: jovens no Rio de Janeiro. Os autores partem da hipótese de que variáveis relacionadas ao local de moradia dos indivíduos ajudam a explicar as escolhas de jovens entre a escola e o mercado de trabalho. Os dados sugerem que as chances de jovens entrarem no mercado de trabalho e abandonarem a escola aumentam significativamente quando estes são residentes de localidades marcadas por moradias de baixo nível socioeconômico, distantes do centro da cidade e com o fato de serem regiões favelizadas.

Além das desigualdades de ofertas escolares e de empregos no território carioca, Sibele Cazelli chama a atenção para a distribuição dos equipamentos culturais, em Jovens, escolas e museus: os efeitos dos diferentes capitais. Na pesquisa feita por Cazelli os jovens de escolas públicas parecem ter mais acesso aos bens culturais da cidade através da escola e menos através da família, no sentido de que a escola é capaz de mobilizar recursos e 
meios para o deslocamento espacial necessário. Desta forma, a autora afirma a importância do capital social baseado na escola para as crianças e jovens das camadas populares no que concerne ao acesso a bens culturais, como por exemplo, os museus. A distribuição desigual dos equipamentos culturais é, portanto, parte de um quadro mais amplo de distribuição hierarquizada das oportunidades educacionais no território.

Para tratar a relação família e escola, o artigo As classes populares e a valorização da educação no Brasil, de Maria Ligia Barbosa e Maria Josefina Sant'Anna, aborda a questão entre o valor conferido pelas famílias à escolarização de seus filhos e os contextos sociais produtores desses sentidos. As autoras constroem alguns indicadores para o que chamam de valor da educação, tais como: distância entre o lugar de moradia e a escola dos filhos, interesse da criança em atividades escolares e a realização dos trabalhos escolares em casa.

Os resultados apresentados baseados nestes indicadores sugerem, entre outras questôes, que a distância entre o lugar de moradia e as escolas escolhidas pelas famílias é significativa. Os pais que apresentam maior investimento e valorização da escolarização dos filhos são os que buscam a melhor qualidade de ensino em escolas que são distantes de sua moradia. De outro modo, os pais que optam por escolas de menor qualidade situadas no bairro, tendem a apresentar menor valorização da educação escolar.

Na segunda parte da coletânea, André Rangel discute em Escola, Jovens e mercado de trabalho: desfiliação institucional na baixada Fluminense os mecanismos que geram o processo de enfraquecimento e fragilidade dos vínculos dos indivíduos com instituições que exercem papel importante no processo de integração social, tais como a escola, a família e o trabalho. Este processo é denominado pelo autor de desfiliação institucional. Através das análises tanto das trajetórias quanto dos discursos de três jovens residentes em regiões segregadas da cidade de São João de Meriti, na Baixada Fluminense, o autor mostra que as trajetórias revelam constantes flutuações entre a formação e a perda dos vínculos institucionais, ou mais especificamente, entre a filiação e a desfiliação das instituições escola e trabalho. Cabe ao território um papel importante neste processo, na medida em que apresenta carências de infra-estrutura urbana e de políticas de fomento à educação, à cultura e ao trabalho. Somado a isso, o artigo trata da dissociação normativa vinculada a distancia simbólica entre a instituição escolar e o universo local no qual esses indivíduos foram socializados.

Os dois últimos artigos da coletânea trazem pesquisas em escolas cujos estudantes são, basicamente, moradores de regiões favelizadas. As pesquisas apontam que o fato da escola estar localizada em regióes pobres ou em regiôes abastadas da cidade, mesmo recebendo alunos com baixo capital cultural, interfere no funcionamento da escola e, como conseqüência, na escolarização das crianças.

Sobre a relação entre família, escola e território, os autores Carolina Zuccarelli e Gabriel Cid abordam no artigo Oportunidades educacionais e escolhas familiares no Rio de Janeiro, as estratégias e escolhas de escolarização de famílias moradoras de duas regiões no bairro de Jacarepaguá que sofreram intenso processo de favelização. Os autores analisaram os discursos e as práticas de escolarização das famílias que escolheram deixar os filhos em escolas localizadas no bairro em que residem e famílias que escolheram uma escola na Barra da Tijuca, bairro próximo a essas duas regiões favelizadas, porém de classe média -alta. A primeira escola apresenta, de acordo com dados do Ministério da Educação, índices muito baixos de qualidade, ao passo que a segunda escola apresenta alto índice de qualidade, sendo uma das melhores da cidade.

Os resultados sugerem que as escolhas dessas famílias por uma ou outra escola não se dão pelos conhecimentos dos índices de qualida- 
de, mas pelo grau de relação estabelecido com o território em que habitam. Nesse sentido, as famílias que possuem fortes laços com as comunidades em que vivem optam por escolarizar seus filhos nestes locais, em contraposição àquelas cujos laços são frágeis com a comunidade. Estas últimas buscam sair do território, na medida em escolhem e traçam estratégias de escolarizar seus filhos em escolas mais distantes, porém de melhor qualidade.

Além disso, a pesquisa etnográfica feita na escola da Barra da Tijuca aponta para o fato da sua qualidade estar muito atrelada à sua localização em um bairro abastado. $\mathrm{Na}$ mesma linha de análise, no artigo A escola na favela ou a favela na escola? de Ana Carolina Christóvão e Mariana Santos, discute-se a qualidade de ensino oferecido aos alunos matriculados em escolas situadas em regiões marcadas pela segregação e o isolamento social.

As autoras apresentam suas pesquisas realizadas em três escolas, duas na Zona Norte e uma na Zona Sul da cidade do Rio de Janeiro, duas situadas nas proximidades de favelas e uma situada dento de uma favela. Os resultados apontaram para um efeito negativo do território na escolarização das crianças. As autoras utilizam o conceito de encapsulamento para afirmar que essas escolas situadas próximo ou dentro de áreas favelizadas acabam sendo envolvidas pela institucionalidade da favela, sofrendo a violência, o estigma e o baixo clima educativo do território.

Vale ressaltar que além desses nove artigos, há dois boxes que fecham cada parte da coletânea. $\mathrm{O}$ primeiro box explora o potencial analítico da PNAD - Pesquisa Nacional por Amostragem de Domicílio em pesquisas sociais e o segundo box descreve o processo de construção da variável Clima Educativo, utilizada em alguns dos artigos do livro.

Por fim, é necessário apontar que os resultados propostos neste livro são de grande valia não só para inserir o tema do território nos estudos da sociologia da educação, mas principalmente para pensar a relevância do território na compreensão dos padróes e mecanismos das desigualdades sociais nas metrópoles urbanas.

\section{Patricia Ramos Novaes}

Assistente Social, mestre em Planejamento

URBANO-IPPUR/UFRJ 